\title{
Regulation of androgen action during establishment of pregnancy
}

\author{
Douglas A Gibson, Ioannis Simitsidellis and Philippa T K Saunders
}

Medical Research Council Centre for Inflammation Research, Queen's Medical Research Institute, University of Edinburgh, Edinburgh, UK

Correspondence should be addressed to D A Gibson

Email

d.a.gibson@ed.ac.uk

\begin{abstract}
During the establishment of pregnancy, the ovarian-derived hormones progesterone and oestradiol regulate remodelling of the endometrium to promote an environment that is able to support and maintain a successful pregnancy. Decidualisation is characterised by differentiation of endometrial stromal cells that secrete growth factors and cytokines that regulate vascular remodelling and immune cell influx. This differentiation process is critical for reproduction, and inadequate decidualisation is implicated in the aetiology of pregnancy disorders such as foetal growth restriction and preeclampsia. In contrast to progesterone and oestradiol, the role of androgens in regulating endometrial function is poorly understood. Androgen receptors are expressed in the endometrium, and androgens are reported to regulate both the transcriptome and the secretome of endometrial stromal cells. In androgen-target tissues, circulating precursors are activated to mediate local effects, and recent studies report that steroid concentrations detected in endometrial tissue are distinct to those detected in the peripheral circulation. New evidence suggests that decidualisation results in dynamic changes in the expression of androgen biosynthetic enzymes, highlighting a role for pre-receptor regulation of androgen action during the establishment of pregnancy. These results suggest that such enzymes could be future therapeutic targets for the treatment of infertility associated with endometrial dysfunction. In conclusion, these data support the hypothesis that androgens play a beneficial role in regulating the establishment and maintenance of pregnancy. Future studies should be focussed on investigating the safety and efficacy of androgen supplementation with the potential for utilisation of novel therapeutics, such as selective androgen receptor modulators, to improve reproductive outcomes in women.
\end{abstract}

Journal of Molecular Endocrinology (2016) 57, R35-R47

\section{Introduction}

The human endometrium is a complex multicellular tissue that undergoes cyclical remodelling in response to fluctuating levels of sex steroid hormones produced by the ovaries (Critchley \& Saunders 2009). The endometrium has epithelial cells on its luminal surface with a multicellular stroma containing fibroblasts, blood vessels (lined with endothelial cells and surrounded by vascular smooth muscle cells), a dynamic immune cell population (including uterine natural killer ( $\mathrm{uNK}$ ) cells and macrophages) as well as glands bounded by a secretory epithelium (King 2000). Women of

\author{
Key Words \\ - androgens \\ - decidualisation \\ - pregnancy \\ - fertility \\ - intracrine
}

reproductive age have high concentrations of circulating hormones derived predominantly from the ovaries and adrenal glands (Abraham 1974). Although concentrations of adrenal hormones are relatively constant, the growth of ovarian follicles and formation of the corpus luteum after ovulation result in fluctuations in the concentrations of ovarian-derived sex steroid hormones across the menstrual cycle. The post-ovulatory rise in progesterone promotes remodelling of the endometrial tissue characterised by decidualisation of endometrial stromal cells (ESCs), 
vascular remodelling and progression to a limited state of receptivity that permits implantation. The regulation of these processes is highly coordinated, both temporally and spatially, within the endometrium. In addition to the established roles of ovarian-derived progesterone and oestradiol, recent evidence supports a role for locally produced intrauterine sex steroids in the regulation of decidualisation, endometrial remodelling and endometrial receptivity. A critical component of this is the regulation of the bioavailability and action of local androgens.

\section{The role of androgen signalling in the regulation of endometrial function}

\section{Androgens in female physiology}

In women, circulating androgens are synthesised predominantly from the ovaries and the adrenal glands, as well as from conversion in peripheral tissues. Circulating concentrations of androgens remain relatively constant throughout the menstrual cycle, exceeding those of oestrogens (Burger 2002, Rothman et al. 2011). The adrenal gland is responsible for secretion of androgen precursors such as dehydroepiandrosterone (DHEA) and its sulphate (DHEAS) as well as the weak androgen androstenedione (A4) and the active androgen testosterone. The ovary produces androgens throughout the menstrual cycle, with peak circulating concentrations of A4 and testosterone detected midcycle coincident with follicular development. Circulating concentrations of the potent endogenous androgen dihydrotestosterone (DHT) are low, but this is largely due to local metabolism within target tissues at the site of action. Sensitive liquid chromatography tandem mass-spectrometry assays have recently been used to detect intratissue androgen concentrations in human endometrium. Initial studies suggest that steroid concentrations in the endometrium are distinct from those in the circulation and may be dysregulated in endometrial pathologies such as endometriosis (Huhtinen et al. 2012, 2014). These new data highlight the capacity for local steroid biosynthesis, metabolism and action within the endometrium, which may impact on endometrial function in health and disease.

\section{AR-dependent signalling and AR expression in the endometrium}

Androgens mediate their actions by binding to the cognate androgen receptor (AR). AR, a member of the nuclear receptor superfamily, is encoded by a single gene on the X chromosome (Kuiper et al. 1989). The spatial organisation of the gene corresponds to the following protein domains: an N-terminal domain (exon 1) with roles in transactivation and interaction with co-factors, a DNA-binding domain responsible for sequence specificity of DNA binding (exons 2-3), a hinge region for nuclear localisation (exon 4) and a C-terminal ligand-binding domain (exons 5-8) that binds steroidal and synthetic ligands (for a review on the roles of AR domains, see Claessens et al. (2008)). Upon ligand binding, AR undergoes conformational changes that result in receptor dimerisation and translocation to the nucleus followed by binding to response elements on enhancers and promoters of target genes and recruitment of co-factors leading to changes in gene expression.

Detection of AR is reported in several female tissues, including the ovaries, adipose, skin, brain, muscle and uterus (Kimura et al. 1993). In the cycling human endometrium, AR is expressed predominantly in stromal fibroblasts of the basal and functional layers during the oestrogen-dominated proliferative phase, with receptor expression reduced during the progesterone-dominated secretory phase of the menstrual cycle (Mertens et al. 2001, Marshall et al. 2011). Although AR is expressed at low levels in endometrial epithelial cells during the secretory phase, the endometrium of women administered with the anti-progestin mifepristone exhibits an elevated expression of AR in epithelial and stromal cells (Slayden et al. 2001, Narvekar et al. 2004). Notably, analysis of full-thickness uterine biopsies demonstrates that AR immunoexpression in endometrial epithelial cells is increased following progesterone withdrawal at the time of menses, consistent with role for progestins in regulating the expression of AR (Marshall et al. 2011). Following the establishment of pregnancy, immunohistochemistry studies have reported that AR is detected in decidual stromal cells and in endothelial cells lining endometrial arteries in first-trimester decidua (Horie et al. 1992, Milne et al. 2005, Critchley \& Saunders 2009).

These findings demonstrate the capacity of the endometrium to function as an androgen-target organ. Furthermore, recent evidence suggests a role for local synthesis of androgens and signalling via intracrine mechanisms within the endometrium (Gibson et al. 2016). Importantly, androgens can also regulate the endometrial function by acting as precursors to oestrogens, which promote spatio-temporal changes within the tissue. Thus, as androgens can act both directly and indirectly to regulate the endometrial function, the expression and activity of androgen-metabolising enzymes within the endometrium

Published by Bioscientifica Ltd 


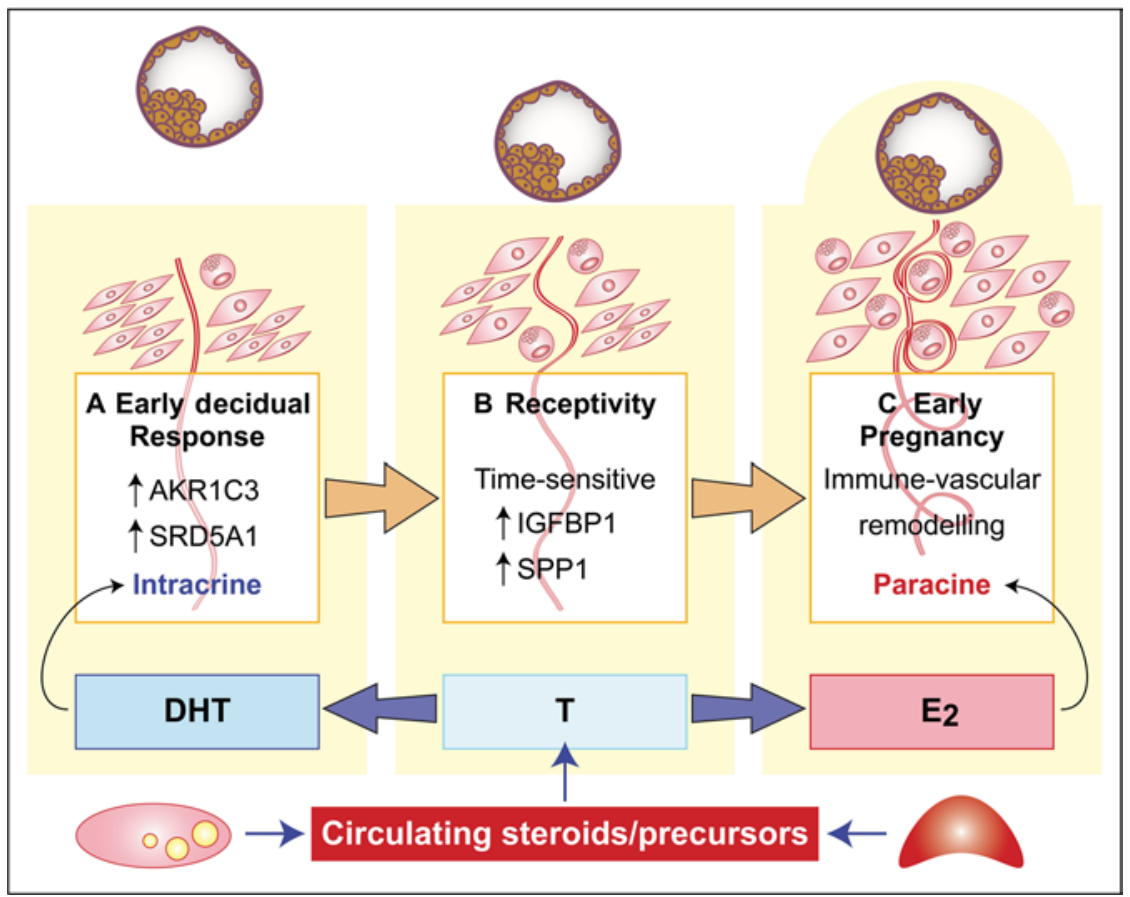

Figure 1

Androgen:oestrogen balance and regulation of the endometrial microenvironment. Decidualisation is associated with changes in local metabolism and synthesis of bioactive androgens, which may be affected by changes in bioavailability of circulating steroid precursors. (A) Increased expression and activity of AKR1C3 early in decidualisation is associated with biosynthesis of testosterone, which is converted to potent androgen DHT by the action of SRD5A1 (Gibson et al. 2016). Testosterone and DHT produced by ESCs during decidualisation signal via an intracrine mechanism to regulate the early decidual response and impact on endometrial transcription of decidualisation and endometrial receptivity factors. (B) Local androgens promote time-sensitive changes in gene transcription during endometrial remodelling, including expression of the decidualisation marker IGFBP1 and the receptivity marker SPP1 (Gibson et al. 2016). Insufficient androgen signalling at this time may promote a transcriptional profile that is 'out of phase', which could impact on endometrial receptivity, blastocyst implantation and the establishment of pregnancy. (C) Regulation of testosterone bioavailability may also impact on the regulation of the endometrium by acting as a precursor to oestrogens. Following induction of aromatase expression in decidualised ESCs (Gibson et al. 2013), local oestrogens regulate immune-mediated vascular remodelling by altering the function of uNK cells in early pregnancy (Gibson et al. 2015).

may represent a key mechanism for controlling steroid bioavailability within the tissue and regulation of endometrial functions (summarised in Fig. 1).

\section{Androgen biosynthesis and expression of steroid- metabolising enzymes in the endometrium}

In androgen-target tissues, peripheral precursors are activated within cells that express the enzymes required for the biosynthesis of androgens. This phenomenon, termed intracrinology, is critical for mediating local responses within tissues without inducing body-wide effects (Labrie 1991). We have recently discovered evidence that supports a role for active steroidogenesis within the endometrium, which significantly extends that in previous reports (summarised in Table 1).

Steroidogenesis involves the formation of active sex steroids via the sequential enzymatic conversion of steroid precursors (for a comprehensive review of steroidogenesis, see Payne \& Hales 2004). Analysis of endometrial tissue homogenates and cells suggests that the endometrium has the capacity for steroidogenesis. Expression of the key steroidogenic enzymes, steroidogenic acute regulatory protein (STAR), cytochrome P450 family 11 subfamily A member 1 (CYP11A1) and cytochrome P450 family 17 subfamily A member 1 (CYP17A1) that convert cholesterol to the common sex steroid hormone precursor DHEA have been reported in the endometrium (Aghajanova et al. 2009, Chen et al. 2011, Huhtinen et al. 2014). STAR mRNA is reported to be expressed at low levels in ESCs but not in epithelial cells (Hukkanen et al. 1998, Rhee et al. 2003, Aghajanova et al. 2009). However, STAR protein levels in total endometrial tissue homogenates detected by western blotting analysis were reported to be low to undetectable (Tsai et al. 2001, Aghajanova et al. 2009, Attar et al. 2009), and to our knowledge, there are no studies reporting CYP11A1 or CYP17A1 protein expression or enzymatic activity in the endometrium.

Published by Bioscientifica Ltd 
Table 1 Expression of steroid biosynthesis enzymes within human endometrium.

\begin{tabular}{|c|c|c|c|c|}
\hline & \multicolumn{2}{|c|}{ Protein } & \multirow{2}{*}{$\begin{array}{c}\text { mRNA } \\
\text { Tissue homogenates }\end{array}$} & \multirow[b]{2}{*}{ References } \\
\hline & Stromal cells & Epithelial cells & & \\
\hline STAR & + & - & + & Tsai et al. (2001) \\
\hline CYP11A1 & + & + & + & $\begin{array}{l}\text { Huhtinen et al. (2014), } \\
\text { Hukkanen et al. } \\
\text { (1998) }\end{array}$ \\
\hline CYP17A1 & ND & ND & + & $\begin{array}{l}\text { Aghajanova et al. } \\
\text { (2009), Huhtinen } \\
\text { et al. (2014) }\end{array}$ \\
\hline$H S D 3 B$ & $\begin{array}{l}\text { Protein detected in isolated } \\
\text { ESCs }\end{array}$ & $\begin{array}{l}\text { Weak in the prolifera- } \\
\text { tive phase and } \\
\text { moderate in the } \\
\text { secretory phase }\end{array}$ & + & $\begin{array}{l}\text { Rhee et al. (2003), } \\
\text { Gibson et al. (2013) }\end{array}$ \\
\hline$H S D 17 B 1$ & + & + & + & $\begin{array}{l}\text { Dassen et al. (2007), } \\
\text { Huhtinen et al. (2012) }\end{array}$ \\
\hline HSD17B2 & $\begin{array}{c}\text { Highest in the secretory } \\
\text { phase }\end{array}$ & $\begin{array}{c}\text { Highest in the secretory } \\
\text { phase, stronger than } \\
\text { stromal }\end{array}$ & + & $\begin{array}{l}\text { Casey et al. (1994), } \\
\text { Dassen et al. (2007), } \\
\text { Huhtinen et al. (2012) }\end{array}$ \\
\hline$A K R 1 C 3$ & $\begin{array}{l}\text { Induced upon } \\
\text { decidualisation }\end{array}$ & $\begin{array}{l}\text { Highest in the early } \\
\text { secretory phase }\end{array}$ & + & $\begin{array}{c}\text { Catalano et al. (2011), } \\
\text { Hevir et al. (2011), } \\
\text { Gibson et al. (2016) }\end{array}$ \\
\hline CYP19A1 & $\begin{array}{l}\text { Induced upon } \\
\text { decidualisation }\end{array}$ & Low/absent & + & $\begin{array}{l}\text { Bulun et al. (1993), } \\
\text { Dassen et al. (2007), } \\
\text { Aghajanova et al. } \\
\text { (2009), Gibson et al. } \\
\text { (2013), Huhtinen } \\
\text { et al. (2014) }\end{array}$ \\
\hline SRD5A1 & + & $\begin{array}{l}\text { All phases of menstrual } \\
\text { cycle }\end{array}$ & + & $\begin{array}{l}\text { Carneiro et al. (2008), } \\
\text { Ito et al. (2002), } \\
\text { Huhtinen et al. } \\
\text { (2014), Gibson et al. } \\
(2016)\end{array}$ \\
\hline
\end{tabular}

Summary of expression of steroid biosynthesis enzymes within the normal endometrium. For abbreviations, see text. Protein detection as reported by immunohistochemistry or western immunoblot. ND, not described.

Rhee and coworkers reported the expression of HSD3B mRNA in the human endometrial tissue homogenates and described 3BHSD protein expression in total endometrial tissue lysates (Rhee et al. 2003). In the same study, glandular epithelial cells immunopositive for 3BHSD were detected in proliferative and secretory phase endometrial samples (Rhee et al. 2003). Immunoexpression was reported to be strongest in the first-trimester decidua and the decidua of ectopic pregnancy consistent with a potential role for this enzyme in decidual steroidogenesis and regulation of early pregnancy. In agreement with these findings, we have detected 3BHSD in isolated proliferative-phase human ESCs by Western blot and immunofluorescence, although expression appears to be constitutive irrespective of whether ESCs were decidualised or not (Gibson et al. 2013). These expression studies are consistent with a capacity for local activation of steroid precursors within the endometrium.

Although expression of many isozymes of the 17BHSD enzyme family has been described in the endometrium, aldo-keto reductase family 1 member C3 (AKR1C3; also known as 17BHSD5) is the most efficient enzyme for the conversion of A4 to testosterone (reviewed in (Rizner \& Penning 2014)). Expression of AKR1C3 in the endometrium was described by Catalano and coworkers who reported peak mRNA expression in endometrial tissue homogenates from the early-secretory phase at a time when early stages of post-ovulatory remodelling and initiation of decidualisation are occurring in the endometrium (Catalano et al. 2011). The same study reported that AKR1C3 was immunolocalised to glandular and luminal epithelial cells throughout the menstrual cycle (Catalano et al. 2011). Reports of

Published by Bioscientifica Ltd 
protein expression in the endometrial stroma have been contradictory, with expression limited to glandular and luminal epithelium as reported by Catalano and coworkers (Catalano et al. 2011); however, Hevir and coworkers demonstrated immunopositive staining in both stromal and epithelial cells (Hevir et al. 2011). Our own studies showed conclusively that AKR1C3 mRNA and protein are both detectable in isolated human ESCs, and decidualisation results in a marked increase in AKR1C3 expression consistent with peak expression reported in the early-secretory-phase endometrial tissue homogenates (Gibson et al. 2016). Interestingly, the mRNA concentration of the oxidative 17BHSD isozyme HSD17B2 (which inactivates testosterone to A4) is reported to be the highest in the endometrial glandular epithelium during the mid-to-late secretory phase, which suggests that active androgens are only bioavailable over a defined window during the secretory phase in the endometrium (Casey et al. 1994). Assessment of androgen biosynthesis during decidualisation of ESCs demonstrated a significant secretion of testosterone detected in cell culture supernatants consistent with a potential role for activation of androgens at this time (Gibson et al. 2016).

A4 is a weak androgen with low affinity for AR, and although testosterone is a potent $\mathrm{AR}$ agonist, either androgen can be converted to oestrogens by the action of the enzyme aromatase. Thus, aromatisable androgens can exhibit dual functionality in controlling androgen:oestrogen balance within the endometrium by acting as activators of $\mathrm{AR}$ and/or as precursors to oestrogens. Although some studies have previously reported that aromatase is not detected in the normal cycling endometrium (Labrie 2015), we have demonstrated conclusively that aromatase can be temporally and spatially regulated during decidualisation (Gibson et al. 2013). Specifically, we have shown that mRNA and protein expression of aromatase is significantly and uniquely upregulated in isolated primary human ESCs resulting in increased aromatase activity and biosynthesis of oestrone and oestradiol (Gibson et al. 2013). Interestingly, Bukulmez and coworkers reported that A4 upregulates aromatase mRNA expression in human ESC and endometrial tissue explants (Bukulmez et al. 2008), underlining the importance of androgens in modulating the steroid microenvironment in the endometrium.

Importantly, testosterone can be also be metabolised to the potent androgen DHT by the enzyme $5 \alpha$-reductase. Notably, DHT exhibits greater affinity for AR than testosterone and cannot be directly converted to oestrogens (Askew et al. 2007). Reports of $5 \alpha$-reductase protein expression in the endometrium have been contradictory; immunohistochemistry studies suggest that expression is limited to epithelial cells (Ito et al. 2002), whereas others have reported immunopositive staining in both stromal and epithelial cells (Carneiro et al. 2008). Metabolism studies using radiolabelled testosterone demonstrated that testosterone can be converted to DHT in human endometrial tissue homogenates (Rose et al. 1978). We have recently investigated the expression and activity of $5 \alpha$-reductase in human ESCs. In this study, we found that $5 \alpha$-reductase was immunolocalised to isolated ESCs and can be detectable in cell lysates by Western blot (Gibson et al. 2016). Notably, although $5 \alpha$-reductase protein expression was detected in both undecidualised and decidualised stromal cells, $5 \alpha$-reductase protein expression decreased in a time-dependent manner in decidualised ESCs (Gibson et al. 2016). In the same study, secretion of DHT was only detected in ESCs that had been stimulated to decidualise; however, the amount of DHT released by the cells declined over time concomitant with decreased $5 \alpha$-reductase protein (Gibson et al. 2016).

These data suggest an extensive capacity for androgen metabolism in the human endometrium, which has received very little attention to date. The endometrium expresses the enzymes required for biosynthesis of androgens and has a capacity for both biosynthesis of testosterone and DHT and metabolic activation of androgen precursors. Notably, activation of androgens appears to be temporally and spatially regulated, and the evidence supports a role for ESCs during the early-secretory-phase producing active androgens within the tissue. Taken together, these studies highlight that during preparation for pregnancy, steroid metabolism in the endometrium promotes a unique hormonal microenvironment, distinct from that of the circulation, which regulates development of a receptive environment for implantation.

\section{Impact of androgens on endometrial function}

\section{Proliferation}

Androgens are reported to have an anti-proliferative effect in the human endometrium. In female-to-male transsexuals, testosterone administration was associated with a reduction in the proliferation indices of glands and stroma, accompanied by endometrial histology similar to that of the atrophic menopausal endometrium (Perrone et al. 2009) and increased immunostaining of AR in the stroma (Chadha et al. 1994). In silico analysis

Published by Bioscientifica Ltd. 
and validation of putative androgen target genes in human proliferative-phase ESCs identified that androgens regulate cellular proliferation and motility in the human endometrium (Marshall et al. 2011). Functional studies confirmed that treatment of human primary ESCs in vitro with the potent androgen DHT significantly decreased cell proliferation and migration as well as AR-dependent inhibition of staurosporin-induced apoptosis (Marshall et al. 2011). Similar effects on proliferation were observed in vitro with human primary endometrial epithelial cells treated with the weak androgen A4; A4 induced a dosedependent decrease in proliferation evident by decreased uptake of ${ }^{3} \mathrm{H}$-thymidine and MKi67 expression, an effect that was reversed after co-incubation with the AR antagonist cyproterone acetate (Tuckerman et al. 2000). However, no similar effect was observed in epithelial cells treated with testosterone or DHT, which may suggest that A4 effects were a result of local metabolism within human endometrial epithelial cells (Tuckerman et al. 2000). Antiprogestin administration in women has been shown to exert anti-proliferative effects on the endometrium, and interestingly, this is reported to be accompanied by an elevated expression of AR in the stroma and the epithelium (Slayden et al. 2001, Narvekar et al. 2004). As treatment with the anti-androgen flutamide reverses the anti-proliferative effect of anti-progestins in the primate endometrium, it has been suggested that the effects of anti-progestins on proliferation may be mediated via AR action (Slayden \& Brenner 2003). In vivo mouse models support a role of androgens in regulating endometrial growth via AR-dependent actions. A mouse model expressing a transgenic luciferase reporter gene under the control of an AR-specific response element (ARE) demonstrated AR expression and activity in the uterus, whereas treatment with the antiandrogen bicalutamide resulted in a significant reduction of detected bioluminescence (Dart et al. 2013). Several global Arknockout mouse models have been generated, targeting different exons of the receptor resulting in either partial or complete loss of the AR protein (Yeh et al. 2002, Shiina et al. 2006, Walters et al. 2007, 2009). However, in global Ar knockout mice, deficits in ovarian function and subfertility phenotypes due to defective folliculogenesis or neuroendocrine defects have precluded extensive insights into the role of AR in uterine function. Notably, $A r^{-1-}$ mice display abnormal uterine growth as evident by a significant reduction in uterine and endometrial surface area at dioestrus and oestrus compared with wildtype (WT) mouse uteri (Walters et al. 2009). In addition, reciprocal ovarian transplantation experiments between
WT and $\mathrm{Ar}^{-1}$ mice showed that ovariectomised $\mathrm{Ar}^{-1}$ hosts implanted with a WT ovary exhibited more pronounced defects in uterine growth than WT hosts with $\mathrm{Ar}^{-1}$ ovaries, suggesting a direct role of intrauterine AR action in regulating uterine growth (Walters et al. 2009). Cellselective ablation of AR has provided further evidence that AR-dependent signalling regulates uterine growth as ovariectomised female mice with targeted $A r$-knockout in the uterine glandular epithelium demonstrate only partial restoration of uterine size after following treatment with testosterone (Choi et al. 2015).

\section{Decidualisation}

Although androgens are known to regulate many processes in female physiology, the potential role(s) in the regulation of the establishment of pregnancy is poorly understood. Decidualisation is the differentiation and proliferation of ESC that is initiated in the secretory phase of the menstrual cycle in response to rising levels of progesterone (reviewed in (Gellersen \& Brosens 2014)). Decidualisation is accompanied by increased angiogenesis and leukocyte infiltration (Plaisier 2011) and is unique to species that undergo haemochorial placentation (Vogiagis \& Salamonsen 1999). Decidualisation is a characterised by the coordinated expression of a specific sets of genes, including those encoding growth factors such as prolactin (PRL) and IGF-binding protein 1 (IGFBP1) and is characterised by the morphological transformation of fibroblastic stromal cells into 'epithelioid' decidual cells during the late secretory phase (Dunn et al. 2003). Decidualised stromal cells are much larger than stromal fibroblasts with rounded nuclei, increased numbers of nucleoli, an expanded secretory apparatus, dilated rough endoplasmic reticulum, and Golgi apparatus and prominent cytoplasmic accumulation of glycogen (Cornillie et al. 1985). In humans, unlike in mice, decidualisation occurs spontaneously in each menstrual cycle and precedes implantation. Transcriptional changes that occur as a result of decidualisation may therefore also impact on endometrial receptivity and implantation. Decidual cells persist in pregnancy and form the maternal component of the placenta, the decidua basalis (Moffett \& Loke 2006). Embryo implantation, placentation and establishment of pregnancy are dependent on adequate decidualisation. Consequently, failure of decidualisation is associated with sub/infertility and implicated in the aetiology of pregnancy disorders, including recurrent pregnancy loss, preeclampsia and foetal growth restriction (Robb et al. 1998, Karpovich et al. 2005).

Published by Bioscientifica Ltd 
Exogenous addition of androgens has been shown to impact on the decidualisation of ESCs. Secretion of the decidualisation marker PRL is significantly increased in human ESCs treated with testosterone or DHT during in vitro decidualisation compared with control treatment, with androgens reported to increase PRL secretion in both a time- and a dose-dependent manner (Narukawa et al. 1994). Both the progesterone receptor (PR) and AR have partially overlapping functions by being able to bind the same response elements and regulate subsets of the same genes (Yen et al. 1997). In vitro decidualisation of primary human ESCs with targeted siRNA knockdown of either PR or AR identified a distinct set of genes regulated only by AR involved in cytoskeletal organisation, cell motility and cell cycle regulation consistent with gene sets identified by in silico analysis (Cloke et al. 2008, Marshall et al. 2011). AR-dependent signalling is reported to regulate the F-actin polymerisation and stress fibre formation, necessary for the acquisition of the motile phenotype of decidual cells (Cloke et al. 2008). Furthermore, DHT is reported to increase resistance to oxidative stress in a dose-dependent manner during in vitro decidualisation of ESCs through regulation of superoxide dismutase 2 (SOD2) expression, which was associated with decreased hydrogen peroxidestimulated apoptosis (Kajihara et al. 2012). Regulation of mitochondrial SOD2 expression may in part be controlled by forkhead box protein O1 (FOXO1), an upstream transcription factor reported to be upregulated in ESCs decidualised in the presence of DHT (Kajihara et al. 2012). In the decidualised endometrium, cells form gap junctions for the exchange of small molecules, and disruption of gap junction formation severely impacts on decidualisation and pregnancy outcomes (Laws et al. 2008, Yu et al. 2011). Kajihara and coworkers reported that treatment with DHT increases connexin-43 protein expression, a structural component of gap junctions, in decidualised human ESCs, which was accompanied by alteration of cellular ultrastructural features, including expansion of intracellular organelles and lipid droplet accumulation, all common features of decidualised cells (Kajihara et al. 2014). Consistent with the roles for exogenous androgens described in human ESCs, in a murine decidualisation model, mice induced to decidualise in the presence of either testosterone or DHT exhibit enhanced responses to decidualisation characterised by increasing deciduoma weight and induction of alkaline phosphatase activity, a marker or decidualisation (Zhang \& Croy 1996). Notably, these effects were reported to be reversed by co-treatment with the AR antagonist hydroxyflutamide consistent with an AR-dependent impact on decidualisation (Zhang \& Croy
1996). Thus, evidence from studies directly manipulating AR expression or activity from the addition of exogenous androgens in human and rodent models has demonstrated a role for androgens in the regulation of decidualisation. The recent description of local pro-androgenic microenvironment that is formed during decidualisation of ESC suggests that intracrine androgens could be the important physiological regulators of decidualisation. In human ESCs, in vitro decidualisation is associated with time-dependent changes in the expression and activity of AKR1C3 and SRD5A1 together with active biosynthesis of the androgens testosterone and DHT (Gibson et al. 2016). Blocking intracrine androgen signalling at the receptor level induced significant changes in the transcriptional profile of ESCs and led to a significant decrease in the expression of key markers of decidualisation PRL and IGFBP1 (Gibson et al. 2016) consistent with an essential role for intracrine androgen signalling during decidualisation.

\section{Implantation}

Establishment of pregnancy involves the attachment and implantation of a competent blastocyst into a receptive endometrium which provides physical and nutritional support during pregnancy (Psychoyos 1973, Aplin 1996). The uterine epithelium is normally hostile to the blastocyst and is required to undergo transition to a receptive state in order for implantation to occur. Uterine receptivity occurs over a restricted period of time during each normal cycle and requires strict spatial and temporal regulation of gene transcription (Koot et al. 2012, Macklon \& Brosns 2014). The receptive phase lasts approximately 4 days in women usually falling on days 20-24 of a standard 28-day cycle (Bergh \& Navot 1992). Following the receptive phase and in the absence of implantation, the uterine epithelium enters a refractory phase and implantation can no longer occur. Transcriptional profiling of endometrial biopsies from across the menstrual cycle and across the proposed window of implantation has identified distinct gene expression patterns associated with different phases of the menstrual cycle and various endometrial pathologies (reviewed in Garrido-Gomez et al. 2013). These studies have been used to generate so-called endometrial receptivity arrays (ERAs) that classify endometrial receptivity according to transcriptomic signature. Reported use of ERAs has included directing personalised embryo transfer (pET) in women with repeated implantation failure (Ruiz-Alonso et al. 2013). Notably, in a pilot study of 17 patients, a greater proportion of clinical and ongoing pregnancies was reported in women following

Published by Bioscientifica Ltd 
pET compared with routine embryo transfer (Ruiz-Alonso et al. 2014). Interestingly, ERA assessment in this pilot study demonstrated that the majority of endometrial biopsies had a transcriptional profile that was assessed as 'pre-receptive' (Ruiz-Alonso et al. 2014). These data indicate that the endometrial profile of these women may be 'out of phase', suggestive of delayed maturation. Although these studies suggest that pET can improve implantation rates in women with repeated implantation failure, timing of implantation itself also has a major impact on the likely success of the pregnancy and the future health of offspring. The majority of pregnancies occur between days 22 and 24 of the menstrual cycle, and delayed implantation is associated with increased rates of early pregnancy loss (Mahendru et al. 2012, Jukic et al. 2013, Macklon \& Brosens 2014). Understanding the mechanisms that may promote endometrial maturation may provide new ways of improving implantation rates in natural as well as assisted reproductive cycles.

Implantation depends on sequential actions of the ovarian sex steroid hormones oestrogen and progesterone. Although progesterone drives priming of the uterus, evidence from studies in rodents suggests that it is oestrogen that is essential for implantation. Oestrogen acting via oestrogen receptor alpha (ER $\alpha$ (ESR1)) transforms the progesterone-primed uterus into a receptive state, and in mice, the uterine oestrogen metabolite catecholestrogen is reported to activate the blastocyst in a paracrine manner (Paria et al. 1998). In mice, bioavailability of oestrogens is a critical determinant of endometrial receptivity; higher levels of oestrogen are associated with aberrant expression of genes normally conducive to implantation, whereas suboptimal levels do not promote progression from the pre-receptive state (Ma et al. 2003). Furthermore, decidualisation is regulated by local de novo oestrogen biosynthesis in mouse uterus. In their study, Das and coworkers demonstrated that inhibiting the action of the enzyme aromatase, which converts androgens to oestrogens, blocks decidualisation and neovascularisation in a model of induced decidualisation (Das et al. 2009). Interestingly, recent studies using isolated human endometrial cells indicate that oestrogens are essential for the regulation of immune cell function and vascular remodelling in early pregnancy (Gibson et al. 2015) but appear to be dispensable for regulation of decidualisation in human ESCs (D A Gibson and $\mathrm{P} \mathrm{T} \mathrm{K}$ Saunders, unpublished observations). Notably, as androgens are precursors to oestrogens, the reported effects of aromatase inhibitors in mouse models could be partly attributed to changes in intrauterine androgen:oestrogen balance. For example, in the model reported by Das and coworkers, the decidualised mouse uterus was reported to express the steroidogenic enzymes necessary for the formation of testosterone (Star, Cyp11a1, Cyp17a1, Hsd3b, Hsd17b1) (Das et al. 2009). Furthermore, $5 \alpha$-reductase activity, as measured by the formation of DHT from radiolabelled testosterone, is significantly increased in the gravid uterine horn of pregnant mice compared with the nongravid horn (Minjarez et al. 2001). In support of a role for androgens in regulation of establishment of pregnancy, it has been reported that androgens can have a direct impact on implantation in mice. Insufficient androgens may delay embryo implantation, whereas excess androgens lead to an aberrant gene expression in implantation sites in a mouse delayed-implantation model (Diao et al. 2008). Similar mechanisms have only recently been explored in human cell systems. For example, we have recently reported that intrauterine androgens promote progesteronedriven decidualisation and regulate the expression of endometrial receptivity markers in human ESCs. Locally produced androgens regulate the expression of secreted phosphoprotein 1 (SPP1), endothelin receptor type B (EDNRB) and monoamine oxidase A (MAOA) (Gibson et al. 2016). SPP1 and EDNRB were significantly reduced when local androgen action was inhibited by the antiandrogen flutamide consistent with a role for androgens in regulating endometrial receptivity in women.

\section{Clinical implications}

Taken together, the data describing the potential role for local androgen signalling in the endometrium suggest that altering the bioavailability of androgen precursors could impact on endometrial function. Notably, adrenal androgen production declines with age, and circulating concentrations of DHEA at age 40 are half than those detected at age 21 (Zumoff et al. 1995). An age-related decline in fertility has often been attributed solely to a decline in ovarian function extrapolating from data on conditions such as premature ovarian failure (POF) or diminished ovarian reserve (DOR). Hypoandrogenism is reported to be associated with DOR and lower pregnancy rates (Gleicher et al. 2013a), and thus, treatment strategies have often focussed on supplementing androgens to improve the ovarian function. The apparent decline in ovarian function is also associated with endometrial senescence, and although this was previously considered secondary to the ovarian function, new data are emerging,

Published by Bioscientifica Ltd. 
highlighting the role of the endometrium itself. Notably, the midcycle peak in androgens is absent in women of advanced reproductive age, and transfer of fertilised oocytes donated by young fertile women to older recipients ( $>40$ years) is associated with reduced implantation rates and higher miscarriage rates than recipients less than 40 years of age (Mushayandebvu et al. 1996, Gupta et al. 2012).

Implantation requires a coordinated regulation of complex hormone-, immune- and growth factordependent signalling processes, and despite advances in in vitro fertilisation (IVF), endometrial receptivity and the subsequent embryo implantation remain the rate-limiting steps. Changes in the availability of circulating androgen precursors may impact on the regulation of implantation by altering intracrine signalling within the endometrium. Supplementation with androgens or androgen precursors has been proposed as a treatment to improve the ovarian function and thus implantation rates. However, there has been a lack of robust clinical evidence to support these approaches, and a number of conflicting studies have been reported. Barad and coworkers reported that in 89 patients with DOR, DHEA supplementation significantly improved clinical pregnancy rates compared with controls, concluding that DHEA supplementation was beneficial in women with DOR (Barad et al. 2007). However, Weissman and coworkers reported that the number of retrieved and fertilised oocytes in women with DOR was similar in women who had or who had not received DHEA supplementation (Weissman et al. 2011). A recent randomised controlled trial (RCT) that investigated the impact of DHEA supplementation in women with poor ovarian reserve undergoing either IVF or intracytoplasmic sperm injection (ICSI) found that pregnancy rates were higher in control groups than in DHEA-treated women (Kara et al. 2014). Notably, despite DHEA supplementation being intended to support the ovarian function in each of these trials, it did not appear to improve the ovarian function measured by either the ovulation rate or the number of fertilised embryos produced. In fact, in the Barad study, the DHEA treatment group produced fewer oocytes, fewer normal day 3 embryos and fewer transferred embryos than the control group, although this is possibly reflected in the greater proportion of DOR in the DHEA group (Barad et al. 2007). Remarkably, almost half of the pregnancies reported in the DHEA group occurred before IVF, i.e. occurred spontaneously, and the DHEA group had a lower rate of miscarriage (Barad et al. 2007). Thus, although not reported by the authors, the positive impacts of DHEA on pregnancy rates described in this study may be due to an impact of DHEA on the endometrium. An important consideration, highlighted by Prizant and coworkers in a recent review, is that not all women respond equally well to DHEA supplementation due to inadequate conversion of DHEA to testosterone (Prizant et al. 2014). Thus, 'non-responders' may not benefit from DHEA supplementation but require direct supplementation with testosterone; however, whether this would be effective in improving pregnancy outcomes in such patients remains to be determined. An increased capacity to convert supplemented DHEA to testosterone was associated with improved IVF pregnancy rates in a prospective study of patients with DOR who received DHEA supplementation for 6 weeks before IVF (Gleicher et al. 2013b) consistent with a role for utilisation and conversion of adrenal precursors in successful pregnancies. Furthermore, a recent metaanalysis of DHEA supplementation in women with DOR undergoing IVF or ICSI assessed evidence from eight studies and concluded that DHEA supplementation improved pregnancy outcomes. DHEA treatment was associated with a significant increase in clinical pregnancy rates (Risk Ratio 2.13); however, there was insufficient power to detect an impact on oocyte retrieval, implantation or miscarriage rates (Li et al. 2015). Thus, although it has been suggested that peripheral androgen supplementation may improve reproductive outcomes in women undergoing IVF, further evidence is required to elucidate the mechanisms by which this may impact on the establishment of pregnancy and specifically on endometrial function.

\section{Summary}

The human endometrium has the capacity for local sex steroid metabolism and synthesis. The relative expression and activities of steroid-metabolising enzymes can alter the local bioavailability of steroids temporally and spatially within the endometrium and thus regulate the endometrial function through activation of steroid hormone receptors. It is clear from studies in rodents as well as those using human cells/ tissues that modulation of endocrine and intracrine androgen signalling affects a number of key functional process in the endometrium, including cell proliferation, apoptosis, resistance to oxidative stress and cell motility. Altering the bioavailability of androgens has an impact on the regulation of establishment of pregnancy through regulation of decidualisation and by directly affecting the expression of endometrial receptivity markers. Furthermore, dysregulation of enzymes that mediate steroid metabolism is an important feature of the pathophysiology of reproductive malignancies

Published by Bioscientifica Ltd. 
and is associated with fertility- and pregnancy-related disorders such as polycystic ovarian syndrome (PCOS) (Apparao et al. 2002), endometriosis (Huhtinen et al. 2012) and recurrent pregnancy loss (Okon et al. 1998).

Given the recently described roles for locally activated oestrogens (Gibson et al. 2013, 2015) and androgens (Gibson et al. 2016) in promoting an optimal microenvironment for pregnancy, regulation of androgen:oestrogen balance has emerged as a key pathway that merits further investigation. The importance of intracrine signalling, particularly through AR, in the uterus should also be taken into account when considering the impact(s) of current therapies that target local steroid metabolism, e.g. aromatase inhibitors, on the uterine function. Evidence using androgen supplementation in IVF suggests a potential benefit to pregnancy rates, but more studies are needed to better understand the impact on ovarian and endometrial function. Although androgen therapies have not been well tolerated in women due to virilising side effects, the generation of selective androgen receptor modulators (SARMs) and novel selective modulators of enzymes such as AKR1C3 may provide a more targeted therapeutic approach without unwanted side effects. Furthermore, androgen therapies in the uterus may also benefit from targeted delivery methods, such as intrauterine devices, which may help to minimise off-target effects and provide effective future therapeutics for modulating the uterine function in health and disease. In the future, greater understanding of local androgen signalling within the endometrium could lead to better understanding of fertility and improved procedures for IVF.

\section{Declaration of interest}

The authors declare that there is no conflict of interest that could be perceived as prejudicing the impartiality of this review.

\section{Funding}

Studies undertaken in the author's laboratory were supported by MRC Programme Grant G1100356/1 to PTKS.

\section{Acknowledgements}

The author thank Ronnie Grant for preparation of figures and members of PTKS group for technical support.

\section{References}

Abraham GE 1974 Ovarian and adrenal contribution to peripheral androgens during the menstrual cycle. Journal of Clinical Endocrinology and Metabolism 39 340-346. (doi:10.1210/jcem-39-2-340)
Aghajanova L, Hamilton A, Kwintkiewicz J, Vo KC \& Giudice LC 2009 Steroidogenic enzyme and key decidualization marker dysregulation in endometrial stromal cells from women with versus without endometriosis. Biology of Reproduction 80 105-114. (doi:10.1095/ biolreprod.108.070300)

Aplin JD 1996 The cell biology of human implantation. Placenta 17 269-275. (doi:10.1016/S0143-4004(96)90050-8)

Apparao KB, Lovely LP, Gui Y, Lininger RA \& Lessey BA 2002 Elevated endometrial androgen receptor expression in women with polycystic ovarian syndrome. Biology of Reproduction 66 297-304. (doi:10.1095/ biolreprod66.2.297)

Askew EB, Gampe RT Jr, Stanley TB, Faggart JL \& Wilson EM 2007 Modulation of androgen receptor activation function 2 by testosterone and dihydrotestosterone. Journal of Biological Chemistry 282 25801-25816. (doi:10.1074/jbc.M703268200)

Attar E, Tokunaga H, Imir G, Yilmaz MB, Redwine D, Putman M, Gurates B, Attar R, Yaegashi N, Hales DB, et al. 2009 Prostaglandin E2 via steroidogenic factor-1 coordinately regulates transcription of steroidogenic genes necessary for estrogen synthesis in endometriosis. Journal of Clinical Endocrinology and Metabolism 94 623-631. (doi:10.1210/jc.2008-1180)

Barad D, Brill H \& Gleicher N 2007 Update on the use of dehydroepiandrosterone supplementation among women with diminished ovarian function. Journal of Assisted Reproduction and Genetics 24 629-634. (doi:10.1007/s10815-007-9178-x)

Bergh PA \& Navot D 1992 The impact of embryonic development and endometrial maturity on the timing of implantation. Fertility and Sterility $\mathbf{5 8} 537-542$.

Bukulmez O, Hardy DB, Carr BR, Auchus RJ, Toloubeydokhti T, Word RA \& Mendelson CR 2008 Androstenedione up-regulation of endometrial aromatase expression via local conversion to estrogen: potential relevance to the pathogenesis of endometriosis. Journal of Clinical Endocrinology and Metabolism 93 3471-3477. (doi:10.1210/jc.2008-0248) Burger HG 2002 Androgen production in women. Fertility and Sterility 77 (Supplement 4) S3-S5. (doi:10.1016/S0015-0282(02)02985-0)

Carneiro MM, Morsch DM, Camargos AF, Reis FM \& Spritzer PM 2008 Androgen receptor and 5alpha-reductase are expressed in pelvic endometriosis. BJOG 115 113-117. (doi:10.1111/j.1471-0528. 2007.01521.x)

Casey ML, MacDonald PC \& Andersson S 199417 beta-Hydroxysteroid dehydrogenase type 2 : chromosomal assignment and progestin regulation of gene expression in human endometrium. Journal of Clinical Investigation 94 2135-2141. (doi:10.1172/JCI117569)

Catalano RD, Wilson MR, Boddy SC \& Jabbour HN 2011 Comprehensive expression analysis of prostanoid enzymes and receptors in the human endometrium across the menstrual cycle. Molecular Human Reproduction 17 182-192. (doi:10.1093/molehr/gaq094)

Chadha S, Pache TD, Huikeshoven JM, Brinkmann AO \& van der Kwast TH 1994 Androgen receptor expression in human ovarian and uterine tissue of long-term androgen-treated transsexual women. Human Pathology 25 1198-1204. (doi:10.1016/0046-8177(94)90037-X)

Chen Y, Saini S, Zaman MS, Hirata H, Shahryari V, Deng G \& Dahiya R 2011 Cytochrome P450 17 (CYP17) is involved in endometrial cancinogenesis through apoptosis and invasion pathways. Molecular Carcinogenesis 50 16-23. (doi:10.1002/mc.20680)

Choi JP, Zheng Y, Skulte KA, Handelsman DJ \& Simanainen U 2015 Development and characterization of uterine glandular epithelium specific androgen receptor knockout mouse model. Biology of Reproduction 93 120. (doi:10.1095/biolreprod.115.132241)

Claessens F, Denayer S, Van Tilborgh N, Kerkhofs S, Helsen C \& Haelens A 2008 Diverse roles of androgen receptor (AR) domains in AR-mediated signaling. Nuclear Receptor Signaling 6 e008. (doi:10.1621/nrs.06008)

Cloke B, Huhtinen K, Fusi L, Kajihara T, Yliheikkila M, Ho KK, Teklenburg G, Lavery S, Jones MC, Trew G, et al. 2008 The androgen and progesterone receptors regulate distinct gene networks and

ed by Bioscientifica Ltd. 
cellular functions in decidualizing endometrium. Endocrinology 149 4462-4474. (doi:10.1210/en.2008-0356)

Cornillie FJ, Lauweryns JM \& Brosens IA 1985 Normal human endometrium. An ultrastructural survey. Gynecologic and Obstetric Investigation 20 113-129. (doi:10.1159/000298983)

Critchley HO \& Saunders PT 2009 Hormone receptor dynamics in a receptive human endometrium. Reproductive Sciences 16 191-199. (doi:10.1177/1933719108331121)

Dart DA, Waxman J, Aboagye EO \& Bevan CL 2013 Visualising androgen receptor activity in male and female mice. PLOS ONE $\mathbf{8}$ e71694. (doi:10.1371/journal.pone.0071694)

Das A, Mantena SR, Kannan A, Evans DB, Bagchi MK \& Bagchi IC 2009 De novo synthesis of estrogen in pregnant uterus is critical for stromal decidualization and angiogenesis. PNAS 106 12542-12547. (doi:10.1073/pnas.0901647106)

Diao HL, Su RW, Tan HN, Li SJ, Lei W, Deng WB \& Yang ZM 2008 Effects of androgen on embryo implantation in the mouse delayedimplantation model. Fertility and Sterility 90 1376-1383. (doi:10.1016/j.fertnstert.2007.07.1341)

Dunn CL, Kelly RW \& Critchley HO 2003 Decidualization of the human endometrial stromal cell: an enigmatic transformation. Reproductive Biomedicine Online 7 151-161. (doi:10.1016/S1472-6483(10)61745-2)

Garrido-Gomez T, Ruiz-Alonso M, Blesa D, Diaz-Gimeno P, Vilella F \& Simon C 2013 Profiling the gene signature of endometrial receptivity: clinical results. Fertility and Sterility 99 1078-1085. (doi:10.1016/j.fertnstert.2012.12.005)

Gellersen B \& Brosens JJ 2014 Cyclic decidualization of the human endometrium in reproductive health and failure. Endocrine Reviews 35 851-905. (doi:10.1210/er.2014-1045)

Gibson DA, McInnes KJ, Critchley HO \& Saunders PT 2013 Endometrial intracrinology - generation of an estrogen-dominated microenvironment in the secretory phase of women. Journal of Clinical Endocrinology and Metabolism 98 E1802-E1806. (doi:10.1210/ jc.2013-2140)

Gibson DA, Greaves E, Critchley HO \& Saunders PT 2015 Estrogendependent regulation of human uterine natural killer cells promotes vascular remodelling via secretion of CCL2. Human Reproduction 30 1290-1301. (doi:10.1093/humrep/dev067)

Gibson DA, Simitsidellis I, Cousins FL, Critchley HO \& Saunders PT 2016 Intracrine androgens enhance decidualization and modulate expression of human endometrial receptivity genes. Scientific Reports 6 19970. (doi:10.1038/srep19970)

Gleicher N, Kim A, Weghofer A, Kushnir VA, Shohat-Tal A, Lazzaroni E, Lee HJ \& Barad DH 2013a Hypoandrogenism in association with diminished functional ovarian reserve. Human Reproduction 28 10841091. (doi:10.1093/humrep/det033)

Gleicher N, Kim A, Weghofer A, Shohat-Tal A, Lazzaroni E, Lee H-J \& Barad DH 2013b Starting and resulting testosterone levels after androgen supplementation determine at all ages in vitro fertilization (IVF) pregnancy rates in women with diminished ovarian reserve (DOR). Journal of Assisted Reproduction and Genetics 30 49-62. (doi:10.1007/s10815-012-9890-z)

Gupta P, Banker M, Patel P \& Joshi B 2012 A study of recipient related predictors of success in oocyte donation program. Journal of Human Reproductive Sciences 5 252-257. (doi:10.4103/0974-1208.106336)

Hevir N, Vouk K, Sinkovec J, Ribic-Pucelj M \& Rizner TL 2011 Aldo-keto reductases AKR1C1, AKR1C2 and AKR1C3 may enhance progesterone metabolism in ovarian endometriosis. ChemicoBiological Interactions 191 217-226. (doi:10.1016/j.cbi.2011.01.003)

Horie K, Takakura K, Imai K, Liao S \& Mori T 1992 Immunohistochemical localization of androgen receptor in the human endometrium, decidua, placenta and pathological conditions of the endometrium. Human Reproduction 7 1461-1466.

Huhtinen K, Desai R, Stahle M, Salminen A, Handelsman DJ, Perheentupa A \& Poutanen M 2012 Endometrial and endometriotic concentrations of estrone and estradiol are determined by local metabolism rather than circulating levels. Journal of Clinical Endocrinology and Metabolism 97 4228-4235. (doi:10.1210/jc.2012-1154)

Huhtinen K, Saloniemi-Heinonen T, Keski-Rahkonen P, Desai R, Laajala D, Stahle M, Hakkinen MR, Awosanya M, Suvitie P, Kujari H, et al. 2014 Intra-tissue steroid profiling indicates differential progesterone and testosterone metabolism in the endometrium and endometriosis lesions. Journal of Clinical Endocrinology and Metabolism 99 E2188-E2197. (doi:10.1210/jc.2014-1913)

Hukkanen J, Mäntylä M, Kangas L, Wirta P, Hakkola J, Paakki P, Evisalmi S, Pelkonen O \& Raunio H 1998 Expression of cytochrome P450 genes encoding enzymes active in the metabolism of tamoxifen in human uterine endometrium. Pharmacology and Toxicology 82 93-97. (doi:10.1111/j.1600-0773.1998.tb01404.x)

Ito K, Suzuki T, Akahira J, Moriya T, Kaneko C, Utsunomiya H, Yaegashi N, Okamura K \& Sasano H 2002 Expression of androgen receptor and 5alpha-reductases in the human normal endometrium and its disorders. International Journal of Cancer 99 652-657. (doi:10.1002/ijc.10394)

Jukic AM, Baird DD, Weinberg CR, McConnaughey DR \& Wilcox AJ 2013 Length of human pregnancy and contributors to its natural variation. Human Reproduction 28 2848-2855. (doi:10.1093/humrep/ det297)

Kajihara T, Tochigi H, Prechapanich J, Uchino S, Itakura A, Brosens JJ \& Ishihara O 2012 Androgen signaling in decidualizing human endometrial stromal cells enhances resistance to oxidative stress. Fertility and Sterility 97 185-191. (doi:10.1016/j.fertnstert.2011.10.017)

Kajihara T, Tanaka K, Oguro T, Tochigi H, Prechapanich J, Uchino S, Itakura A, Sucurovic S, Murakami K, Brosens JJ, et al. 2014 Androgens modulate the morphological characteristics of human endometrial stromal cells decidualized in vitro. Reproductive Sciences 21 372-380. (doi:10.1177/1933719113497280)

Kara M, Aydin T, Aran T, Turktekin N \& Ozdemir B 2014 Does dehydroepiandrosterone supplementation really affect IVF-ICSI outcome in women with poor ovarian reserve? European Journal of Obstetrics \& Gynecology and Reproductive Biology 173 63-65. (doi:10.1016/j.ejogrb.2013.11.008)

Karpovich N, Klemmt P, Hwang JH, McVeigh JE, Heath JK, Barlow DH \& Mardon HJ 2005 The production of interleukin-11 and decidualization are compromised in endometrial stromal cells derived from patients with infertility. Journal of Clinical Endocrinology and Metabolism 90 1607-1612. (doi:10.1210/jc.2004-0868)

Kimura N, Mizokami A, Oonuma T, Sasano H \& Nagura H 1993 Immunocytochemical localization of androgen receptor with polyclonal antibody in paraffin-embedded human tissues. Journal of Histochemistry and Cytochemistry 41 671-678. (doi:10.1177/41.5.8468448)

King A 2000 Uterine leukocytes and decidualization. Human Reproduction Update 6 28-36. (doi:10.1093/humupd/6.1.28)

Koot YE, Teklenburg G, Salker MS, Brosens JJ \& Macklon NS 2012 Molecular aspects of implantation failure. Biochimica et Biophysica Acta 1822 1943-1950. (doi:10.1016/j.bbadis.2012.05.017)

Kuiper GG, Faber PW, van Rooij HC, van der Korput JA, Ris-Stalpers C, Klaassen P, Trapman J \& Brinkmann AO 1989 Structural organization of the human androgen receptor gene. Journal of Molecular Endocrinology 2 R1-R4.

Labrie F 1991 Intracrinology. Molecular and Cellular Endocrinology 78 C113-C118. (doi:10.1016/0303-7207(91)90116-A)

Labrie F 2015 All sex steroids are made intracellularly in peripheral tissues by the mechanisms of intracrinology after menopause. Journal of Steroid Biochemistry and Molecular Biology 145 133-138. (doi:10.1016/j.jsbmb.2014.06.001)

Laws MJ, Taylor RN, Sidell N, DeMayo FJ, Lydon JP, Gutstein DE, Bagchi MK \& Bagchi IC 2008 Gap junction communication between uterine stromal cells plays a critical role in pregnancy-associated neovascularization and embryo survival. Development 135 2659-2668. (doi:10.1242/dev.019810) 
Li J, Yuan H, Chen Y, Wu H, Wu H \& Li L 2015 A meta-analysis of dehydroepiandrosterone supplementation among women with diminished ovarian reserve undergoing in vitro fertilization or intracytoplasmic sperm injection. International Journal of Gynecology \& Obstetrics 131 240-245. (doi:10.1016/j.ijgo.2015.06.028)

Ma WG, Song H, Das SK, Paria BC \& Dey SK 2003 Estrogen is a critical determinant that specifies the duration of the window of uterine receptivity for implantation. PNAS 100 2963-2968. (doi:10.1073/ pnas.0530162100)

Macklon NS \& Brosens JJ 2014 The human endometrium as a sensor of embryo quality. Biology of Reproduction 91 98. (doi:10.1095/ biolreprod.114.122846)

Mahendru AA, Daemen A, Everett TR, Wilkinson IB, McEniery CM, Abdallah Y, Timmerman D, Bourne T \& Lees CC 2012 Impact of ovulation and implantation timing on first-trimester crown-rump length and gestational age. Ultrasound in Obstetrics \& Gynecology 40 630-635. (doi:10.1002/uog.12277)

Marshall E, Lowrey J, MacPherson S, Maybin JA, Collins F, Critchley HO \& Saunders PT 2011 In silico analysis identifies a novel role for androgens in the regulation of human endometrial apoptosis. Journal of Clinical Endocrinology and Metabolism 96 E1746-E1755. (doi:10.1210/jc.2011-0272)

Mertens HJ, Heineman MJ, Theunissen PH, de Jong FH \& Evers JL 2001 Androgen, estrogen and progesterone receptor expression in the human uterus during the menstrual cycle. European Journal of Obstetrics \& Gynecology and Reproductive Biology 98 58-65. (doi:10.1016/S0301-2115(00)00554-6)

Milne SA, Henderson TA, Kelly RW, Saunders PT, Baird DT \& Critchley HO 2005 Leukocyte populations and steroid receptor expression in human first-trimester decidua: regulation by antiprogestin and prostaglandin E analog. Journal of Clinical Endocrinology and Metabolism 90 4315-4321. (doi:10.1210/jc.2004-2338)

Minjarez D, Konda V \& Word RA 2001 Regulation of uterine 5 alphareductase type 1 in mice. Biology of Reproduction 65 1378-1382. (doi:10.1095/biolreprod65.5.1378)

Moffett A \& Loke C 2006 Immunology of placentation in eutherian mammals. Nature Reviews Immunology 6 584-594. (doi:10.1038/nri1897)

Mushayandebvu T, Castracane VD, Gimpel T, Adel T \& Santoro N 1996 Evidence for diminished midcycle ovarian androgen production in older reproductive aged women. Fertility and Sterility 65 721-723.

Narukawa S, Kanzaki H, Inoue T, Imai K, Higuchi T, Hatayama H, Kariya M \& Mori T 1994 Androgens induce prolactin production by human endometrial stromal cells in vitro. Journal of Clinical Endocrinology and Metabolism 78 165-168. (doi:10.1210/ jcem.78.1.8288699)

Narvekar N, Cameron S, Critchley HO, Lin S, Cheng L \& Baird DT 2004 Low-dose mifepristone inhibits endometrial proliferation and up-regulates androgen receptor. Journal of Clinical Endocrinology and Metabolism 89 2491-2497. (doi:10.1210/jc.2003-031945)

Okon MA, Laird SM, Tuckerman EM \& Li TC 1998 Serum androgen levels in women who have recurrent miscarriages and their correlation with markers of endometrial function. Fertility and Sterility 69 682-690. (doi:10.1016/S0015-0282(98)00007-7)

Paria BC, Lim H, Wang XN, Liehr J, Das SK \& Dey SK 1998 Coordination of differential effects of primary estrogen and catecholestrogen on two distinct targets mediates embryo implantation in the mouse. Endocrinology 139 5235-5246. (doi:10.1210/endo.139.12.6386)

Payne AH \& Hales DB 2004 Overview of steroidogenic enzymes in the pathway from cholesterol to active steroid hormones. Endocrine Reviews 25 947-970. (doi:10.1210/er.2003-0030)

Perrone AM, Cerpolini S, Maria Salfi NC, Ceccarelli C, De Giorgi LB, Formelli G, Casadio P, Ghi T, Pelusi G, Pelusi C, et al. 2009 Effect of long-term testosterone administration on the endometrium of female-to-male (FtM) transsexuals. Journal of Sexual Medicine 6 3193-3200. (doi:10.1111/j.1743-6109.2009.01380.x)
Plaisier M 2011 Decidualisation and angiogenesis. Best Practice \& Research Clinical Obstetrics \& Gynaecology 25 259-271. (doi:10.1016/j. bpobgyn.2010.10.011)

Prizant H, Gleicher N \& Sen A 2014 Androgen actions in the ovary: balance is key. Journal of Endocrinology 222 R141-R151. (doi:10.1530/ JOE-14-0296)

Psychoyos A 1973 Hormonal control of ovoimplantation. Vitamins \& Hormones 31 201-256.

Rhee HS, Oh SH, Ko BJ, Han DM, Jeon BH, Park H, Moon HB \& Kim WS 2003 Expression of 3beta-hydroxysteroid dehydrogenase and P450 side chain cleavage enzyme in the human uterine endometrium. Experimental and Molecular Medicine 35 160-166. (doi:10.1038/ emm.2003.22)

Rizner TL \& Penning TM 2014 Role of aldo-keto reductase family 1 (AKR1) enzymes in human steroid metabolism. Steroids 79 49-63. (doi:10.1016/j.steroids.2013.10.012)

Robb L, Li R, Hartley L, Nandurkar HH, Koentgen F \& Begley CG 1998 Infertility in female mice lacking the receptor for interleukin 11 is due to a defective uterine response to implantation. Nature Medicine 4 303-308. (doi:10.1038/nm0398-303)

Rose LI, Reddy VV \& Biondi R 1978 Reduction of testosterone to 5 alpha-dihydrotestosterone by human and rat uterine tissues. Journal of Clinical Endocrinology and Metabolism 46 766-769. (doi:10.1210/ jcem-46-5-766)

Rothman MS, Carlson NE, Xu M, Wang C, Swerdloff R, Lee P, Goh VH, Ridgway EC \& Wierman ME 2011 Reexamination of testosterone, dihydrotestosterone, estradiol and estrone levels across the menstrual cycle and in postmenopausal women measured by liquid chromatography-tandem mass spectrometry. Steroids 76 177-182. (doi:10.1016/j.steroids.2010.10.010)

Ruiz-Alonso M, Blesa D, Diaz-Gimeno P, Gomez E, FernandezSanchez M, Carranza F, Carrera J, Vilella F, Pellicer A \& Simon C 2013 The endometrial receptivity array for diagnosis and personalized embryo transfer as a treatment for patients with repeated implantation failure. Fertility and Sterility 100 818-824. (doi:10.1016/j.fertnstert.2013.05.004)

Ruiz-Alonso M, Galindo N, Pellicer A \& Simon C 2014 What a difference two days make: 'personalized' embryo transfer (pET) paradigm: a case report and pilot study. Human Reproduction 29 1244-1247.

Shiina H, Matsumoto T, Sato T, Igarashi K, Miyamoto J, Takemasa S, Sakari M, Takada I, Nakamura T, Metzger D, et al. 2006 Premature ovarian failure in androgen receptor-deficient mice. PNAS 103 224-229. (doi:10.1073/pnas.0506736102)

Slayden OD \& Brenner RM 2003 Flutamide counteracts the antiproliferative effects of antiprogestins in the primate endometrium. Journal of Clinical Endocrinology and Metabolism 88 946-949. (doi:10.1210/jc.2002-021763)

Slayden OD, Nayak NR, Burton KA, Chwalisz K, Cameron ST, Critchley HO, Baird DT \& Brenner RM 2001 Progesterone antagonists increase androgen receptor expression in the rhesus macaque and human endometrium. Journal of Clinical Endocrinology and Metabolism 86 2668-2679. (doi:10.1210/ jcem.86.6.7606)

Tsai SJ, Wu MH, Lin CC, Sun HS \& Chen HM 2001 Regulation of steroidogenic acute regulatory protein expression and progesterone production in endometriotic stromal cells. Journal of Clinical Endocrinology and Metabolism 86 5765-5773. (doi:10.1210/ jcem.86.12.8082)

Tuckerman EM, Okon MA, Li T \& Laird SM 2000 Do androgens have a direct effect on endometrial function? An in vitro study. Fertility and Sterility 74 771-779. (doi:10.1016/S0015-0282(00) 00711-1)

Vogiagis D \& Salamonsen LA 1999 Review: the role of leukaemia inhibitory factor in the establishment of pregnancy. Journal of Endocrinology 160 181-190. (doi:10.1677/joe.0.1600181) 
Walters KA, Allan CM, Jimenez M, Lim PR, Davey RA, Zajac JD, Illingworth P \& Handelsman DJ 2007 Female mice haploinsufficient for an inactivated androgen receptor (AR) exhibit age-dependent defects that resemble the AR null phenotype of dysfunctional late follicle development, ovulation, and fertility. Endocrinology 148 3674-3684. (doi:10.1210/en.2007-0248)

Walters KA, McTavish KJ, Seneviratne MG, Jimenez M, McMahon AC, Allan CM, Salamonsen LA \& Handelsman DJ 2009 Subfertile female androgen receptor knockout mice exhibit defects in neuroendocrine signaling, intraovarian function, and uterine development but not uterine function. Endocrinology 150 3274-3282. (doi:10.1210/ en.2008-1750)

Weissman A, Horowitz E, Ravhon A, Golan A \& Levran D 2011 Dehydroepiandrosterone supplementation increases baseline follicular phase progesterone levels. Gynecological Endocrinology $\mathbf{2 7}$ 1014-1017. (doi:10.3109/09513590.2011.569611)

Yeh S, Tsai MY, Xu Q, Mu XM, Lardy H, Huang KE, Lin H, Yeh SD, Altuwaijri S, Zhou X, et al. 2002 Generation and characterization of androgen receptor knockout (ARKO) mice: an in vivo model for the study of androgen functions in selective tissues. PNAS 99 13498-13503. (doi:10.1073/pnas.212474399)

Yen PM, Liu Y, Palvimo JJ, Trifiro M, Whang J, Pinsky L, Jänne OA \& Chin WW 1997 Mutant and wild-type androgen receptors exhibit cross-talk on androgen-, glucocorticoid-, and progesterone-mediated transcription. Molecular Endocrinology 11 162-171. (doi:10.1210/ mend.11.2.9886)

Yu J, Wu J, Bagchi IC, Bagchi MK, Sidell N \& Taylor RN 2011 Disruption of gap junctions reduces biomarkers of decidualization and angiogenesis and increases inflammatory mediators in human endometrial stromal cell cultures. Molecular and Cellular Endocrinology 344 25-34. (doi:10.1016/j.mce.2011.04.011)

Zhang X \& Croy BA 1996 Maintenance of decidual cell reaction by androgens in the mouse. Biology of Reproduction 55 519-524. (doi:10.1095/biolreprod55.3.519)

Zumoff B, Strain GW, Miller LK \& Rosner W 1995 Twenty-four-hour mean plasma testosterone concentration declines with age in normal premenopausal women. Journal of Clinical Endocrinology and Metabolism 80 1429-1430.

Received in final form 4 April 2016

Accepted 11 April 2016

Accepted Preprint published online 11 April 2016
C 2016 Society for Endocrinology Printed in Great Britain
Published by Bioscientifica Ltd 